\title{
ANÁLISE DO CURSO DE GRADUAÇÃO EM ADMINISTRAÇÃO A SOB A ÓTICA DOS SISTEMAS ADAPTATIVOS COMPLEXOS
}

\author{
Andressa Sasaki Vasques Pacheco - EGC/UFSC - andressa.ufsc@gmail.com \\ Maurício Rissi-CPGA/UFSC - mauriciorissiadm@gmail.com \\ Joel Gregorio Perozo Vasquez - EGC/UFSC - joelperozo@gmail.com \\ Marina Keiko Nakayama - EGC/UFSC - marina@egc.ufsc.br \\ Pedro Antônio de Melo - CPGA/UFSC - pedromelo@inpeau.ufsc.br
}

\section{RESUMO}

O Governo brasileiro vem incentivando ações para o desenvolvimento da EaD nas IES, tendo como um dos pontos principais dessa ação a Universidade Aberta do Brasil (UAB) na qual está inserida o projeto piloto do curso de Administração a distância. Conhecer a complexidade de organizações de ensino torna-se não só importante, mas essencial para o seu desenvolvimento e conhecimento. Este foi o objetivo deste trabalho, por meio da descrição de diversos fatores como: agentes, estratégias, padrões de interação, artefatos, espaço físico e conceitual, cópia, recombinação e seleção. Pode-se concluir que o curso de Administração a distância da UFSC possui todas as características relacionadas por Axelrod e Cohen (2000), mas o desenvolvimento deve ser contínuo, e sempre monitorado, buscando agregar os princípios da complexidade e da gestão do conhecimento.

Palavras-chaves: Complexidade. Educação a distância.

\section{ANALYSIS ADMINISTRATION GRADUATION COURSE BY THE OPTICS OF COMPLEX SYSTEMS}

\section{ABSTRACT}

Brazilian Government comes stimulating action for the development of the EaD in the IES, having as the one of the main points of this action Open University of Brazil (UAB) in which is inserted the project pilot of the Administration course by distance. To know the complexity of education organizations not only becomes important, but essential for its development and knowledge. This was the objective of this work, by means of the description of diverse factors as: agents, strategies, standards of interaction, devices, physical and conceptual space, copy, recombination and election. It can be concluded that the course of Administration in the distance of the UFSC possesss all the characteristics related for Axelrod and Cohen (2000), but the development must be continuous, and always monitored, searching to add the principles of the complexity and the management of the knowledge. 
Key-words: Complexity. Distance Education.

\title{
1 INTRODUÇÃO
}

A UNESCO (1997) destaca que a aceleração vertiginosa no desenvolvimento das tecnologias de informação e de comunicação passou a configurar um desafio e até um questionamento da adequação dos sistemas tradicionais de ensino, mas, simultaneamente, passou a oferecer também parcerias na criação de uma ampla gama de novas oportunidades de aprendizagem sem restrições de tempo e espaço.

Neste contexto, a modalidade de educação a distância foi potencializada, culminando em uma educação cada vez mais próxima e personalizada, além de privilegiar a troca de conhecimentos em rede e, com isso, instigar o surgimento de comunidades de aprendizagem (ABRAED, 2007). Complementa-se ainda que

\begin{abstract}
a Educação a Distância - EaD tende doravante a se tornar cada vez mais um elemento regular dos sistemas educativos, necessário não apenas para atender a demandas e/ou grupo específicos, mas assumindo funções de crescente importância, especialmente no ensino pós-secundário, ou seja, na educação da população adulta, o que inclui o ensino superior regular e toda a grande e variada demanda de formação contínua gerada pela obsolescência acelerada da tecnologia e do conhecimento (BELLONI, 2006, p.4-5).
\end{abstract}

Nesse sentido, a EaD apresenta-se como um importante instrumento de intercâmbio e articulação de conhecimento e informações entre diferentes comunidades virtuais de aprendizagem.

Assim, o conjunto das instituições participantes do Fórum das Estatais da Educação propôs a criação do Sistema Universidade Aberta do Brasil (UAB), que congrega instituições públicas de educação superior para ofertar cursos e programas da modalidade a distância, tendo como ponto de partida a consolidação e a diversificação de experiências, em variados níveis de ensino, que vêm gradativamente tomando forma no país (ABRAED, 2007).

O Sistema Universidade Aberta do Brasil, implantado em 2005, representa assim a convergência de esforços das instituições participantes do Fórum das Estatais pela Educação para o estabelecimento das bases da primeira UAB do país e tem se consolidado por meio de amplos e democráticos debates, particularmente por meio da interlocução do Governo Federal com empresas públicas, estatais e a Associação Nacional dos Dirigentes das Instituições Federais de Ensino Superior (Andifes).

Essa parceria apresenta um quadro promissor, tendo em vista o desafio de combater o cenário brasileiro desfavorável: o país ainda figura entre as nações mais excludentes do mundo, no que diz respeito ao acesso ao ensino superior, pois 
dados do INEP - Instituto Nacional de Estudos e Pesquisas Educacionais Anísio Teixeira de 2005 indicam que apenas em torno de 10,9\% dos jovens com idade entre 18 e 24 anos têm acesso à educação superior presencial (ABRAED, 2007).

A Universidade Federal de Santa Catarina (UFSC) é uma das instituições que aderiram a essa parceria. Com uma experiência nacionalmente reconhecida e responsável por 52\% da publicação nacional sobre EaD (ABRAED, 2007) a UFSC tem ampliado o contingente de estudantes por meio do ensino a distância.

Inserido nessa ampliação do ensino, tem-se o projeto piloto de um curso de graduação em Administração a distância. Este projeto está presente em mais de 20 estados brasileiros e é resultado de uma parceria entre a UAB - Universidade Aberta do Brasil (projeto pertencente ao Ministério da Educação - MEC) e Banco do Brasil.

Em Santa Catarina, este curso teve início no dia 10 de julho de 2006, e é destinado aos funcionários do Banco do Brasil, servidores da UFSC e outros servidores públicos da esfera federal, estadual e municipal. O curso iniciou suas atividades com 654 alunos, em dez pólos espraiados pelo Estado de Santa Catarina: Araranguá, Canoinhas, Chapecó, Criciúma, Florianópolis, Joinville, Lages, Laguna, Palhoça e Tubarão. Têm-se atualmente duas reedições do curso, uma para o Estado de Santa Catarina e outro para pólos UAB destinados pelo MEC.

Assim, percebe-se a importância dessa modalidade e dessas iniciativas de ensino. Com isso, este trabalho tem como objetivo analisar o curso de graduação em Administração a distância de acordo com os conceitos de sistemas adaptativos complexos. Pois, para Moresi (2001), a complexidade oferece um caminho para descobrir e adotar um novo paradigma, porque reconhece que as organizações são sistemas complexos, não lineares, sem equilíbrio estável, de dinâmica imprevisível e fornece um arcabouço teórico para entender essa dinâmica.

Apresenta-se a seguir os conceitos inerentes à complexidade.

\section{COMPLEXIDADE}

Talvez o avanço mais importante das últimas décadas foi a percepção de que o mundo é fundamentalmente não linear (ORMEROD, 1994 apud MORESI, 2001). Assim, pode-se admitir que estudos lineares certamente não darão conta da não linearidade do mundo. As organizações por sua vez, comportam-se de forma também não linear, necessitando assim de uma compreensão mais ampla para que possa dar conta de sua dinâmica. Como já mencionado, Moresi (2001) diz que a complexidade é a resposta para essa não linearidade, pois, acredita que ela forneça um arcabouço teórico capaz de entender essa dinâmica não linear das organizações.

Mas o que é complexidade? Ou o que são sistemas complexos? Muitas são as definições que procuram esclarecer o conceito de complexidade, para esse propósito é mais importante algumas características do que a própria definição. $\mathrm{E}$ certamente a característica mais relevante nesse contexto é a dita por Anderson (1996, apud MORESI, 2001, p.49) "Sistemas complexos tendem a exibir comportamento auto-organizado, isso é, começando em um estado aleatório, eles podem evoluir naturalmente para ordem em vez de desordem". 
Outra compreensão importante da complexidade é, para Morrin (apud LOUREIRO, 2005, p.única), "que se refere ao sentido de que a vida, em suas manifestações, se constitui por dimensões interconectas, definidas mutuamente nas relações estabelecidas, envolvendo ordem e desordem, erro e acerto, compromisso e intransigência, risco e certeza, numa autoprodução e reorganização permanente." Essa capacidade da complexidade em tratar de questões ambíguas faz com que seus estudos possam dar conta da complexidade inerente ao mundo da vida e por conseqüência, das organizações.

Outro fator importante de um sistema complexo é sua simplicidade. Isso, dito de outra forma nas palavras de Moresi $(2001$, p.66),

a lição mais importante da teoria da complexidade é que sistemas complexos dinâmicos geram ordem criativa e se adaptam a mudanças em seus ambientes, por interações simples entre os seus agentes, e que pequenas mudanças podem conduzir frequentemente a grandes efeitos. A ordem não é imposta por planejamento de cima para baixo, ela emerge de baixo para cima.

Para demonstrar essa "simplicidade" de sistemas complexos Caulkin (1995, apud MORESI, 2001) cita um fato interessante demonstrado pelo pesquisador Mitchell Waldrop, ele apresentou um programa de computador que simula o vôo de pássaros em bandos. Programando cada "pássaro" virtual individualmente, com apenas três regras simples, ele demonstrou o vôo dessas "aves" como acontece na vida real. Não havia nenhuma instrução de como os "pássaros" deviam se comportar coletivamente, apenas as instruções: manter um mínimo de distância um do outro; tentar voar à mesma velocidade; e tomar a dianteira quanto estivessem em grande concentração. Essas três regras simples eram capazes de demonstrar um padrão variante e complexo de comportamento.

Para Moresi (2001) os sistemas complexos adaptativos são sistemas/fenômenos distintos mas com várias características em comum. São complexos pois estão muito além da capacidade descritiva da nossa ciência e são adaptativos pois são capazes de se adaptar a novas condições que the são impostas pelo seu ambiente.

Tratando de Sistemas Adaptativos Complexos, Axelrod e Cohen (2000, p.103104) listam alguns conceitos, e uma breve definição, que consideram centrais para a abordagem complexa de uma organização. Os conceitos são:

a) Estratégia, um padrão de ação condicional que indica o que fazer em quais circunstâncias.

b) Artefato, um recurso material que tem localização definida e pode reagir às ações dos agentes.

c) Agente, uma coleção de propriedades (especialmente localização), estratégias, e habilidades para a interação com artefatos e outros agentes.

d) População, uma coleção de agentes, ou, em algumas situações, coleções de estratégias.

e) Sistema, uma coleção maior, incluindo uma ou mais populações de agentes e possivelmente também artefatos. 
f) Tipo, todos os agentes (ou estratégias) numa população que têm algumas características em comum.

g) Variedade, a diversidade de tipos dentro de uma população ou sistema.

h) Padrão de interação, as regularidades de contato recorrentes entre tipos dentro de um sistema.

i) Espaço (físico), a localização no espaço e tempo geográficos de agentes e artefatos.

j) Espaço (conceitual), a "localização" num conjunto de categorias estruturadas a fim de que agentes "próximos" tenderão a interagir.

k) Seleção, processos que levam a um aumento ou diminuição na freqüência de vários tipos de agentes ou estratégias.

I) Critério de sucesso ou medida de desempenho, um "placar" usado por um agente ou designer para atribuir crédito na seleção de estratégias ou agentes relativamente bemsucedidos (ou malsucedidos).

Sabe-se que pode emergir de regras simples sistemas complexos conforme já demonstrado na simulação de vôo dos pássaros. Se não são as regras, os artefatos, as estratégias, etc. o que tornam um sistema complexo? Para responder isso podese valer de uma definição dada por Axelrod e Cohen (2000, p.11) dizendo que "um sistema é complexo quando há fortes interações entre seus elementos, de forma tal que os eventos atuais influenciem pesadamente as probabilidades de muitos tipos de eventos posteriores". Assim, afirma-se que a complexidade emerge das interações de seus agentes. Como no caso dos "pássaros" a interação entre eles formam o complexo comportamento da coletividade.

Axelrod e Cohen (2000, p.27) tratam de alguns temas que consideram essenciais para um Sistema Adaptativo Complexo são eles a Variação; a Interação e a Seleção. Os autores afirmam que "A variedade dentro de uma população é uma exigência central para a adaptação." Pois, é ela que fornece a matéria prima da adaptação, criando dentro do sistema um equilíbrio entre variedade e uniformidade. Há várias formas de se prover variedade dentro de um sistema, por exemplo: "A morte é o mecanismo de transformação mais óbvio, destruindo agentes e possivelmente destruindo um tipo se todas as suas instâncias morrem, como aconteceu com os dinossauros. O nascimento cria novos agentes"(AXELROD; COHEN, 2000, p.31). Além desses, nos sistemas biológicos, "um dos mais importantes é o cruzamento, um processo de recombinar contribuições genéticas de cada um dos pais. Este mecanismo cria tipos originais, mas com um método amplamente distinto da mutação."(AXELROD; COHEN, 2000, p.33)

Quando se fala de interação, necessária em qualquer sistema complexo, deve-se observar alguns aspectos que as tornam possíveis, um deles é a localização e para Axelrod e Cohen (2000, p.49) "a localização próxima no espaço faz com que os eventos de interação sejam mais prováveis para uma vasta gama de processos". Mas a interação não ocorre somente com agentes próximos fisicamente, e a partir disso Axelrod e Cohen (2000) diz que "com a idéia de espaço físico, podemos usar a idéia como uma analogia e falar a respeito da localização de agentes e interações 
em espaços conceituais também. Por exemplo, um gráfico de organização fornece um mapa de um espaço conceitual (AXELROD; COHEN, 2000, p.53)

Para ressaltar a importância da interação Axelrod e Cohen (2000, p.46) dizem que

As interações fazem um Sistema Adaptativo Complexo ficar vivo. 0 sistema se torna, não um mero amontoado de agentes de tipos variados, mas uma população que dá origem a eventos e têm uma história se desenrolando. Esses eventos induzem processos de seleção e expansão que no final das contas mudam a freqüência e a variedade de tipos de agente, como vamos explorar no próximo capítulo. Padrões de interação ajudam a determinar o que será bem-sucedido para os agentes e o sistema, e isto, por sua vez, ajuda a moldar a dinâmica dos próprios padrões de interação.

\title{
Complementa-se ainda que
}

\begin{abstract}
Um agente tem a habilidade de interagir com o seu meio, incluindo outros agentes. Um agente pode reagir ao que acontece à sua volta e pode fazer coisas mais ou menos propositadamente. Com maior freqüência, pensamos num agente como uma pessoa, tal qual o membro da equipe numa empresa ou a pessoa buscando o empréstimo. Considerando esta ampla definição, podemos julgar que uma pessoa não é o único tipo de agente. Uma família, um negócio ou um país inteiro também podem ser um agente. Até um programa de computador interagindo com outros programas pode ser visto como um agente (AXELROD; COHEN, 2000, p.9)
\end{abstract}

Visto a variação e interação e seus conceitos os autores Axelrod e Cohen (2000, p.11) se detém ao processo de Seleção que pode ser o resultado de mecanismos tais como o aprendizado por tentativa-e-erro, ou a imitação de estratégias de agentes aparentemente bem-sucedidos.

A seleção ainda segundo esses autores "pode resultar de mudanças populacionais como nascimento e morte, contratação e demissão, imigração e emigração, ou abertura e falência". (AXELROD; COHEN, 2000, p.11)

A evolução biológica funciona pela seleção de agentes. O sucesso de um organismo leva à reprodução. Isto não impõe nenhuma determinação de quais dos genes "merecem" crédito pelo sucesso reprodutivo. Em vez disso, todos os genes no organismo em reprodução têm uma chance, grosso modo, igual, de serem passados adiante para a prole. (AXELROD; COHEN, 2000, p.88) 
Para esses autores a variação, a interação e a seleção são conceitos entrelaçados que podem gerar ações produtivas num mundo que não pode ser plenamente compreendido.

Um outro conceito-chave é estratégia, a maneira pela qual um agente reage ao seu meio e persegue seus objetivos (AXELROD; COHEN, 2000). "Em muitos Sistemas Adaptativos Complexos, todas as estratégias dos agentes são parte do contexto no qual cada agente está atuando. Isto torna difícil para o agente prever as conseqüências de suas ações e portanto eleger o melhor curso de ação" (AXELROD; COHEN, 2000, p.11).

Finalizando Axelrod e Cohen sintetizam que "Agentes, de uma variedade de tipos, usam suas estratégias, em interação padronizada, uns com os outros e com artefatos. Medidas de desempenho sobre os eventos resultantes impulsionam a seleção de agentes e/ou estratégias através de processos de cópia e recombinação propensos ao erro, mudando assim as freqüências dos tipos dentro do sistema. (AXELROD; COHEN, 2000, p.104)"

\section{ESTUDO DE CASO}

Neste capítulo é abordada a caracterização da organização, bem como a análise de sua complexidade. A coleta de dados deu-se por meio de observação participante, sendo que um dos autores deste artigo fazia parte da equipe de tutoria do curso de graduação a distância da UFSC.

\subsection{Caracterização da Organização}

Criada em 1960, a Universidade Federal de Santa Catarina (UFSC) consolidou-se como uma das melhores instituições de ensino superior do Brasil e da América Latina. É protagonista de muitas ações no campo da pesquisa e produção científica, nos intercâmbios e projetos de mobilidade acadêmica e nas trocas constantes de experiências com investigadores e organismos de alta competência.

Atualmente são oferecidos 62 cursos de Graduação, 48 cursos de Mestrado e 33 de Doutorado, além do Ensino Básico no Colégio de Aplicação. Seu corpo docente alcança o invejável índice de mais de $90 \%$ de Mestres e Doutores. A UFSC conta com 32.286 estudantes na modalidade presencial.

Reconhecendo a indissociabilidade entre ensino, pesquisa e extensão, e a importância da divulgação e popularização da ciência, a instituição persegue, nos seus 47 anos, os objetivos de estimular a reflexão crítica e de colaborar com a qualidade de vida da sociedade em geral. Para isso, desenvolve também atividades de extensão junto a outras universidades, prefeituras, governo estadual, órgãos federais, instituições nacionais e internacionais e movimentos sociais. 
A UFSC é uma das instituições que aderiram a modalidade a distância. Com o incentivo de um projeto da Universidade Aberta, a UFSC tem ampliado o contingente de estudantes atingidos por meio do ensino a distância.

Desde 1995, a UFSC vem oferecendo cursos que beneficiam diversos profissionais atuantes em todo o país. Inicialmente, ofertando cursos de extensão para a Secretaria de Estado da Educação de Santa Catarina, cursos de pós graduação em nível de mestrado e também formação de professores com cursos de complementação em Química, Física, Matemática e Biologia.

Atualmente, uma das políticas do Governo Federal é a ampliação do acesso ao ensino superior, incluindo-se aí a formação dos servidores públicos. O Curso de Graduação em Administração foi um dos escolhidos devido a sua importância para a formação de agentes de mudança, sobretudo no processo de desenvolvimento sócio-econômico do país.

Nesse contexto e em resposta à demanda motivada pelo Ministério de Educação, com a finalidade de atender às necessidades das empresas estatais em termos de qualificação dos seus servidores públicos, a Universidade Federal de Santa Catarina - UFSC, juntamente com outras instituições de ensino superior, participou do projeto de criação do Curso de Graduação em Administração, na modalidade a distância, como um programa da Universidade Aberta do Brasil UAB/MEC.

Tal projeto segue o que está disposto no Decreto № 5707, de 23 de fevereiro de 2006, que instituiu a Política e as Diretrizes para o Desenvolvimento de Pessoal da administração pública federal direta, autárquica e fundacional, e regulamenta dispositivos da Lei № 8.112, de 11 de dezembro de 1990.

Cabe destacar que a Universidade Federal de Santa Catarina já conta com a oferta de um Curso de Graduação em Administração na forma presencial reconhecido pela resolução 10063/2003. A adoção da oferta de um curso na modalidade a distância é resultante tanto da necessidade de atender aos estudantes residentes em regiões sem instituições de ensino superior, como também profissionais em serviço que necessitam de formação em nível universitário.

De acordo com o projeto pedagógico, o objetivo geral do curso de graduação em Administração a Distância ministrado pela UFSC é o de formar o profissional administrador para atuar na micro, pequena e média empresa (pública e privada) dotado de capacidade empreendedora, capacidade analítica para elaborar diagnósticos, propor mudanças, visão sistêmica e, que conduza dentro da ética as empresas a atenderem as necessidades da sociedade.

A formação em Administração exige das atividades do Curso de Graduação ter como orientação fundamental seu inter-relacionamento e uma natureza, preponderantemente, sistemática, procurando ultrapassar os limites da mera formação profissional, abrangendo, inclusive, conteúdos informativos sobre as ações administrativas no setor público e privado. Após o concurso vestibular realizado em março de 2006, realizado pela Coperve (Comissão Permanente de vestibular) alcançando-se um número de 654 matriculados, após sete chamadas. Entre eles encontram-se funcionários do Banco do Brasil (50\% dos estudantes) e 
servidores públicos federais, estaduais e municipais atuando em órgãos situados no Estado de Santa Catarina e portadores de diploma de ensino médio.

O curso conta com dez pólos de ensino em todo o Estado de Santa Catarina: Araranguá, Criciúma, Laguna, Palhoça, Florianópolis, Tubarão, Joinville, Canoinhas, Lages e Chapecó. Nesses municípios, a UFSC disponibiliza aos estudantes pólos de estudo com infra-estrutura técnica e pedagógica (coordenador de pólo e tutor presencial) que são utilizados para as atividades presenciais e como base de apoio para os estudos, durante todo o curso.

Em 2008 houve reedição do curso para os pólos de Santa Catarina, sendo oferecido mais 400 vagas. E também a abertura de 600 vagas em 15 pólos fora do Estado, sendo eles: Mata de São João-BA; Cidade Gaúcha-PR; Cruzeiro do OestePR; Paranaguá-PR; Hulha Negra-RS; Jacuizinho-RS; São Francisco de Paula-RS; Seberi-RS; Tapejara-RS; Tio Hugo-RS; Boa Vista-RR; Bonfim-RR; Caroebe-RR; MucajaíRR; Uiramutã-RR.

O currículo do Curso de Graduação em Administração na modalidade a distância tem como pressuposto a concepção de educação contínua e permanente, que possa ser oferecida pelas instituições educativas de forma aberta, sem restrições, exclusões ou privilégios.

A carga horária total do curso é de 3000 (três mil) horas / aula, sendo a maior parte ministrada a distância e não mais que $20 \%$ presencial. As atividades presenciais constituem-se de encontros, seminários temáticos e exames. O curso terá duração de no mínimo quatro anos e meio e no máximo cinco anos, organizados em nove módulos.

Quanto à dinâmica do curso, estabeleceu-se que cada ano é composto de dois módulos, sendo um por semestre. Os estudos têm como referência básica o material impresso, o ambiente virtual de aprendizagem, as vídeo-aulas, as videoconferências com os professores e o sistema de acompanhamento ao estudante (tutoria).

Ressalta-se que as disciplinas têm sua data de início e término já estipuladas previamente pela coordenação do curso, ficando ao encargo do professor o planejamento do cronograma e a produção das atividades realizadas dentro deste período de tempo.

O curso conta com a seguinte equipe de apoio: 2 Tutores Supervisores por turma, 1 Tutor a Distância e 1 Tutor Presencial a cada 25 alunos, 1 Coordenador do Curso e 1 Coordenador da tutoria, além de uma Comissão Coordenadora (7 professores) e o Conselho Editorial (4 professores).

Destaca-se a função dos tutores a distância os quais são facilitadores da aprendizagem, motivando e estimulando os estudantes a realizarem as atividades, esclarecendo dúvidas, reforçando a aprendizagem e também coletando informações sobre os estudantes (desempenho, notas, atividades realizadas, opiniões e sugestões). São eles os responsáveis pelo envio, recebimento e correção de atividades ao seu grupo de estudantes. 


\subsection{Análise da Complexidade na Educação a Distância CAD/UFSC}

Analisa-se a seguir os fatores referentes aos sistemas adaptativos complexos: agentes, estratégias, padrões de interação, artefatos, espaço físico e conceitual, cópia, recombinação e seleção.

\subsubsection{Agentes, tipos e variedades}

O Curso de Administração oferecido na modalidade a distância pela Universidade Federal de Santa Catarina conta com vários tipos de agentes e com ampla variedade. Dentre os agentes que fazem parte do processo, podemos destacar: Coordenador de Curso; Coordenador de Tutoria; Comissão Editorial; Supervisores de Tutoria; Professores; e Tutores; Alunos.

Pode-se considerar o EAD do curso de administração com ampla variedade de tipos, pois, envolvidos no processo encontra-se desde professores com formação específica em determinada área, alunos com as mais variadas diferenças (idades; formação; regiões; etc.), tutores para mediar a aprendizagem do aluno, e vários outros agentes cada um com sua especificidade, contribuindo para o processo de formação.

\subsubsection{Estratégias}

A estratégia do Curso de Administração a Distância é dada basicamente pelo seu projeto pedagógico, onde, em linhas gerais, apresenta o funcionamento do curso como um todo, e a ementa de cada uma das disciplinas do curso. Além da estratégia dada pelo projeto pedagógico, tem também os ajustes à estratégia, pois como o projeto é algo novo para o departamento, faz-se necessário ajustes na estratégia quando detecta-se que a estratégia em uso é inadequada ou não obtem os resultados esperados.

\subsubsection{Padrão de interação}


Quanto a interação, ela ocorre de diferentes formas para os diferentes grupos de agentes, o curso procura contemplar uma amplitude alta de interação para compensar uma possível dificuldade da mesma, em virtude da distância. Dessa forma, tem-se mais de um padrão de interação para cada grupo de agentes. Os principais são: professor-aluno; professor-tutor; tutor-aluno. A interação professor-aluno é basicamente nas vídeo-aulas; videoconferências; e chats.

\subsubsection{Artefatos}

A variedade de artefatos utilizados é bastante alta, no entanto, grande parte da interação se da por meios virtuais. Sendo assim, os artefatos computacionais (computadores; rede; ambientes virtuais; emails; etc) são quase a totalidade do tempo de uso dos artefatos. Porém, além desses, tem outros artefatos de grande importância, como os materiais didáticos disponíveis, biblioteca, e etc.)

\subsubsection{Espaços físico e conceitual}

Os espaços físicos utilizados pelo EaD são formados por diferentes arranjos. $\mathrm{Na}$ sede da instituição o curso utiliza uma sala para os tutores, uma para treinamento e outra para a equipe de edição de materiais. Para gravação e edição das vídeo-aulas e videoconferências, é utilizado por meio de parceria, a estrutura física do LED (Laboratório de Educação a Distância). A coordenação e professores utilizam as suas próprias salas já cedidas pela instituição para o curso presencial. Nos pólos de ensino são utilizados espaços cedidos pelas prefeituras locais. Cada prefeitura, ao solicitar o curso para sua cidade, se compromete em fornecer espaço físico necessário ao desenvolvimento do curso.

Os espaços conceituais são ainda mais intrincados. Além das interações inerentes do curso com cada uma das comunidades atendidas, tem a proximidade conceitual, com alguns órgãos do MEC, com várias instâncias dentro da instituição, cujo merece destaque o DEaD (Departamento de Educação a Distância), o NPD (Núcleo de Processamento de Dados), e o LED já mencionado.

\subsubsection{Cópia, recombinação e seleção}

A cópia e a recombinação no curso de Administração a distância ocorrem principalmente em estratégias. Por exemplo, o projeto pedagógico é uma recombinação de outros projetos, assim como também as ementas das disciplinas são recombinações das ementas disponíveis das instituições que se propuseram a discutí-las. 
A seleção é utilizada para aumentar a freqüência de um tipo de agente específico, o tutor. Este sofre o processo de seleção e nele é preferível que tenha algumas características em detrimento de outras. Portanto, para o agente tutor é frequentemente utilizado a seleção para alterar as características do grupo, como já foi feito uma vez, por uma exigência do MEC ao solicitar que todos deviam ter graduação na área, alterando a freqüência relativa, que era predominantemente graduandos para predominantemente graduados.

A seleção também é utilizada para o agente aluno, porém, para este não é focado uma característica particular, mas sim um conjunto mínimos de conhecimentos.

\section{CONSIDERAÇÕES FINAIS}

A educação é uma das principais bases para o crescimento econômico e social de um país. A expansão da educação superior no Brasil, devido à sua extensão territorial, é um desafio para os governantes. A educação a distância vem ao encontro deste desafio, podendo minimizar os problemas territoriais e democratizar a educação superior no país.

Para isso, o Governo brasileiro vem incentivando ações para o desenvolvimento da EaD nas IES, tendo como um dos pontos principais dessa ação a Universidade Aberta do Brasil (UAB) na qual está inserida o projeto piloto do curso de Administração a distância.

As informações obtidas nesse artigo vêm agregar diversas áreas, podendo ser percebida a multidisciplinariedade deste trabalho. Para Terra (2001), a gestão do conhecimento implica a adoção de práticas gerenciais compatíveis com os processos de criação e aprendizado individual e, também, na coordenação sistêmica de esforços em vários planos: organizacional e individual; estratégico e operacional; normas formais e informais.

Complementa-se ainda que para gerir o conhecimento é uma atividade que requer metodologias adequadas, planejamento estruturado, para que os objetivos organizacionais sejam alcançados em qualquer área de atuação. No que diz respeito à educação, o assunto torna-se ainda mais importante, pelo fato de que a aprendizagem é o objetivo final desse tipo de instituição. Sendo que, além de uma proposta pedagógica consistente, é necessário à coordenação dos procedimentos adotados para a criação, armazenamento e disseminação do conhecimento, bem como o controle do mesmo.

Fialho (2007) ainda complementa que em métodos tradicionais de ensino, o conhecimento tem sido separado do contexto no qual ele é produzido. A situação e atividade de um conhecimento produz a cognição de conceitos funcionais deste conhecimento. 
Jorge (2006) destaca que graças à complexidade, seria possível recuperar a unidade perdida dos saberes, único modo de conhecer e de compreender uma realidade que se mutila se se dividir.

Agrega-se ainda que

\begin{abstract}
A pesquisa da complexidade nos dá uma base fundamentada para indagar onde os "pontos de alavancagem" e as trocas significativas de um sistema complexo podem estar. Ela também sugere que tipos de situações podem ser resistentes à intervenção de uma política, e quando pequenas intervenções apresentam maior probabilidade de ter grandes efeitos. Para guiar no planejamento de ações, estas percepções das questões corretas podem ser muito valiosas. Elas podem ser valiosas mesmo que as teorias sejam múltiplas e preliminares demais para apoiar qualquer declaração de que uma teoria da complexidade implica alguma expectativa claramente entalhada sobre um cenário futuro e sobre como uma ação particular vai garanti-lo. (AXELROD; COHEN, 2000, p.20-21)
\end{abstract}

Assim, conhecer a complexidade de organizações de ensino torna-se não só importante, mas essencial para o seu desenvolvimento e conhecimento. Este foi o objetivo deste trabalho, por meio da descrição de diversos fatores como: agentes, estratégias, padrões de interação, artefatos, espaço físico e conceitual, cópia, recombinação e seleção.

Pode-se concluir que o curso de Administração a distância da UFSC possui todas as características relacionadas por Axelrod e Cohen (2000), mas o desenvolvimento deve ser contínuo, e sempre monitorado, buscando agregar os princípios da complexidade e da gestão do conhecimento.

\title{
REFERÊNCIAS
}

ABRAEAD - Anuário Brasileiro Estatístico de Educação Aberta e a Distância. 3.ed. São Paulo: Instituto Monitor, 2007.

AXELROD, Robert M.; COHEN, Michael D. Harnessing complexity: organizational implications of a scientific frontier. Tradução livre. New York: The Free Press, 2000.

BARBERÀ, Elena (coord). Educación abierta y a distancia. Barcelona: UOC, 2006.

BELLONI, Maria Luiza. Educação a distância. 4 ed. Campinas: Autores Associados, 2006.

EaD-UFSC. Educação a distância da Universidade Federal de Santa Catarina. Disponível em <www.ead.ufsc.br>. Acesso em nov.2008.

FIALHO, Francisco Antonio Pereira. Introdução às Ciências da Cognição. 2.ed. Florianópolis: 2007 
JORGE, Maria Manuel Araújo. O impacto epistemológico das investigações sobre "complexidade". Sociologias [online]. 2006, no. 15, pp. 24-55. ISSN 1517-4522. doi: $10.1590 /$ S1517-45222006000100003

LOUREIRO, Carlos Frederico Bernardo. Complexidade e dialética: contribuições à práxis política e emancipatória em educação ambiental. Educ. Soc. [online]. 2005, vol. 26, no. 93, pp. 1473-1494. ISSN 0101-7330. doi: 10.1590/S0101-73302005000400020

MORESI, Eduardo Amadeu Dutra.Monitoração ambiental e complexidade. 2001. 191 f. Tese (Doutorado) - Curso de Ciência da Informação, Departamento de Ciência da Informação e Documentação, Universidade de Brasília, Brasilia, 2001.

NEVES, Clarissa Eckert Baeta; NEVES, Fabrício Monteiro. O que há de complexo no mundo complexo? Niklas Luhmann e a Teoria dos Sistemas Sociais. Sociologias [online]. 2006, no. 15, pp. 182-207. ISSN 1517-4522. doi: 10.1590/S1517-45222006000100007.

TERRA, José Cláudio Cyrineu. Gestão do conhecimento: aspectos atuais. In: Fleury, Maria Tereza Leme (org.); OLIVEIRA JR., Moacir de Miranda (org.). Gestão estratégica do conhecimento: integrando aprendizagem, conhecimento e competências. São Paulo: Atlas, 2001.

UFSC. Universidade Federal de Santa Catarina. Site institucional. Disponível em <www.ufsc.br>. Acesso em nov. 2008.

UNESCO. Aprendizagem aberta e a distância: perspectivas e considerações políticas educacionais. Florianópolis: Imprensa Universitária, UFSC, 1997. 